\title{
Biochemical and serological analysis of Vibrio anguillarum related organisms
}

\author{
Ysabel Santos*, Francisco Pazos, Alicia E. Toranzo \\ Departamento de Microbiología y Parasitología, Facultad de Biología, Universidad de Santiago, \\ E-15706 Santiago de Compostela, Spain
}

\begin{abstract}
This work reports on the phenotypic and serological characterization of Vibrio anguillarum related (VAR) organisms isolated from diseased fish, shellfish, and from the environment in different geographical areas. Reference strains of $V$. anguillarum (serotypes O1 to O10) and $V$. splendidus (biotype I) were included for comparison. On the basis of numerical taxonomy analysis the strains were grouped in 4 phena, with similarity levels among them ranging from 77.6 to $86.8 \%$ and levels of internal similarity ranging from 84.1 to $86.8 \%$. The serological analysis demonstrated that 22 of 45 $(49 \%)$ VAR strains were typeable, being distributed into 7 O-serogroups ( $A, B, C, D, E, F, G)$. Six of these serogroups ( $A, B, C, D, F$, and $G$ ) were recognized among 21 VAR strains isolated from diseased fish. Serotypes $C$ and $F$ were the predominant types among strains isolated from diseased turbot and cod, respectively. No dominating environmental serotype was found. Moreover, it was found that only serogroup F constituted a heterogeneous group with regard to phenotypic and serological characteristics.
\end{abstract}

KEY WORDS: Vibrio anguillarum related organısms $\cdot$ O-Serotyping $\cdot$ Fish $\cdot$ Shellfish $\cdot$ Environment

\section{INTRODUCTION}

Vibriosis is considered to be one of the most serious threats to the success of fish culture industry, occurring worldwide. The disease also affects farmed bivalve molluscs and crustaceans (Toranzo \& Barja 1990). Although Vibrio anguillarum (serotypes $\mathrm{O} 1, \mathrm{O} 2$, and O3) is considered the main causative agent of vibriosis in marine fish, other Vibrio species taxonomically related to $V$. anguillarum have been associated with disease in larval and adult stages of marine fish (Masumura et al. 1989, Fouz et al. 1990, Toranzo et al. 1990, Myhr et al. 1991, Pazos et al. 1993) and shellfish (Lavilla-Pitogo et al. 1990, Paillard \& Maes 1990, Castro et al. 1992, Riquelme et al. 1995) in different geographical areas. These vibrios correspond to different biotypes of $V$. splendidus and $V$. pelagius and can be grouped under the designation $V$. anguillarum like or $V$. anguillarum related (VAR) organisms (Bryant et al. 1986a, Fouz et al. 1990, Toranzo \& Barja 1990, Myhr

•E-mail:mpaetjlb@usc.es et al. 1991, Pazos et al. 1993, Riquelme et al. 1995). At present, vaccines which contain antigen preparations of $V$. anguillarum of the serotypes $\mathrm{O} 1$ and $\mathrm{O} 2$ (subgroups $\alpha$ and $\beta$ ) have proved to be very effective for the control of vibriosis (Santos et al. 1991). However, VAR organisms have been isolated from vaccinated fishes (Myhr et al. 1991, Pazos et al. 1993). This fact emphasizes the need to carry out an extensive characterization of VAR isolates in order to determine if representative strains of this organism should be included in the vibriosis vaccines. In this sense, previous studies have demonstrated that VAR strains can be differentiated from $V$. anguillarum on the basis of biochemical characteristics (Bryant et al. 1986a, Fouz et al. 1990, Myhr et al. 1991, Pazos et al. 1993) and that the VAR strains do not share antigenic components with the serotypes $\mathrm{O} 1$ to $\mathrm{O} 5$ of $\mathrm{V}$. anguillarum (Pazos et al. 1993). In the present paper we report the phenotypic and serological characterization of VAR organisms isolated from diseased fish, shellfish, and the environment in different countries (Chile, Denmark, Spain, United States). 


\section{MATERIALS AND METHODS}

Bacterial strains and phenotypic characterization. In the present work we used 45 strains, isolated from diseased fish (34 strains), shellfish (2 strains), and the environment ( 9 strains) in our area (Spain) and other countries (Chile, Denmark, Norway, United States) (Table 1). Gram stain, oxidase and catalase tests, morphology and motility, growth on thiosulfate citrate bile sucrose (TCBS) agar (Oxoid, Basingstoke, England), fermentation of glucose, nitrate reduction, and sensitivity to the vibriostatic agent 2,4-diamino-6,7-disopropylpteridine (O/129) (Oxoid) were used to identify the isolates as members of the genus Vibrio. Reference strains of $V$. anguillarum (serotypes $\mathrm{O} 1$ to $\mathrm{O} 10$ ) and $V$. splendidus (biotype I) from the American Type Culture Collection (ATCC) were also included for comparative purposes (Table 1).

All the strains were examined using a total of 41 physiological and biochemical tests. The assays were performed following the criteria of Bryant et al. (1986a, b), Fouz et al. (1990), and Myhr et al. (1991). The results of the phenotypic tests of the 56 strains were subjected to numerical taxonomic analyses. Similarity among the strains was calculated by using the simple matching coefficient. Clustering was carried out using the unweighted pair group method with arithmetic averages (UPGMA) (Sneath 1972).

Source of antisera. Seven representative VAR strains (RM51, RC25.1, RPM30.2, RM36.1, 95-3-35, 953-72, 95-3-88) with distinct isolation sources and displaying phenotypical differences, and the strain of Vibrio splendidus ATCC 33125 (biotype I), were used to obtain the antisera. Sera were obtained in rabbits as described by Sørensen \& Larsen (1986) using formalinkilled cells as antigen. Whole-cell antisera against reference strains of $V$. anguillarum (serotypes $\mathrm{O} 1$ to $\mathrm{O} 10$ ) were kindly provided by J. L. Larsen (Department of Veterinary Microbiology, Royal Veterinary and Agricultural University, Frediksberg, Denmark).

Serological assays. The serological relationships between strains were determined by slide agglutination and quantitative agglutination tests following basically the procedures of Sørensen \& Larsen (1986) and Santos et al. (1995). The assays were performed using the heat stable $\mathrm{O}$-antigen and rabbit whole-cell antisera. The $\mathrm{O}$-antigens were prepared by heating bacterial suspensions of each strain in phosphatebuffered saline (PBS) at $100^{\circ} \mathrm{C}$ for $1 \mathrm{~h}$. Slide agglutination tests were conducted by mixing a drop of each $\mathrm{O}$ antigen suspension $\left(10^{9}\right.$ cells $\mathrm{ml}^{-1}$, McFarland standard No. 3) with a drop of $1 / 10$ diluted rabbit antiserum on a multiwell glass slide. A visible and immediate agglutination was registered as positive and no or only a weak agglutination occurring after 1 to $2 \mathrm{~min}$ as a negative reaction. Quantitative agglutination tests were performed in microtiter plates using serial 2 -fold dilutions of $50 \mu \mathrm{l}$ aliquots of the antisera and $\mathrm{O}$-antigen suspensions ( $10^{9}$ cells $\mathrm{m}^{-1}, \mathrm{McF}$ arland standard No. 3 ). The agglutination titer was considered the reciprocal of the highest dilution of the antiserum giving a positive reaction after incubation with the antigen overnight at $15^{\circ} \mathrm{C}$.

\section{RESULTS}

\section{Phenotypical characterization and numerical taxonomy analysis}

The results of the biochemical and physiological characterization (Table 2) indicated that all of the strains were rod shaped, motile, Gram-negative, oxidase and catalase positive, halophilic, and negative for lysine and ornithine decarboxylases. All the strains fermented D-glucose without gas production, reduced nitrate, and were sensitive to the vibriostatic agent $\mathrm{O} / 129$. None of the isolates grew at $44^{\circ} \mathrm{C}$, and none produced acid from inositol or rhamnose. In the remaining biochemical tests, variation among the strains was detected (Table 2 ). The results of the assays for susceptibility to chemotherapeutic agents showed that the majority of the Vibrio strains were sensitive to chloramphenicol and tetracycline, resistant to streptomycin, and variable in their susceptibility to the other chemotherapeutic compounds assayed.

The results of numerical analysis of the strains are presented in Fig. 1 and Table 2. The isolates were distributed in 4 phena, defined at similarity levels of $86.8 \%$ (phenon I), 84.6\% (phenon II), 86.5\% (phenon III), and $84.1 \%$ (phenon IV). Similarity levels among phena ranged from 77.6 to $86.8 \%$. Phenon I, which comprised 14 strains, included the majority of the $V i b$ rio anguillarum reference strains ( 7 of 10 strains tested). All the isolates of this group were positive for Voges-Proskauer, indole, $\beta$-galactosidase, gelatinase, and caseinase. The majority of the strains produced acid from arabinose, mannitol, sorbitol, and amygdalin. Phenon II contained 23 strains (including the remaining reference strains of $V$. anguillarum) which were lecithinase positive and hemolytic (using turbot erythrocytes), and most of them produced acid from amygdalin and mannitol. Most of the strains of this group lacked elastase activity and did not produce acid from arabinose. The majority of the environmental strains ( 8 of 9 isolates tested) were included in this phenon. Phenon III was composed of 8 strains (including the reference strain of $V$. splendidus biotype I) which did not produce yellow colonies on TCBS or acid from sorbitol and arabinose, and lacked elastase activity. 
Table 1. Bacterial strains used in the present study. Data in parentheses indicate serotype or biotype

\begin{tabular}{|c|c|c|c|}
\hline Strain & Species & Isolated from & Donor \\
\hline $\operatorname{ATCC} 43305(\mathrm{O} 1)$ & V. anguillarum & Oncorhynchus mykiss (Denmark) & ATCC \\
\hline $\operatorname{ATCC} 43306(\mathrm{O} 2)$ & V. anguillarum & Gadus morhua (Denmark) & ATCC \\
\hline $\operatorname{ATCC} 43307(03)$ & V. anguillarum & Oncorhynchus mykiss (Denmark) & ATCC \\
\hline ATCC $43308(04)$ & V. anguillarum & Gadus morhua (Denmark) & ATCC \\
\hline ATCC 43309 (O5) & $V$. anguillarum & Gadus morhua (Denmark) & ATCC \\
\hline ATCC $43310(O 6)$ & $V$ anguillarum & Gadus morhua (Denmark) & ATCC \\
\hline $\operatorname{ATCC} 43311(\mathrm{O})$ & $V$ anguillarum & Anguilla anguilla (Denmark) & ATCC \\
\hline ATCC $43312(08)$ & $V$ anguillarum & Gadus morhua (Denmark) & ATCC \\
\hline ATCC 43313 (O9) & $V$. anguillarum & Gadus morhua (Denmark) & ATCC \\
\hline ATCC $43314(010)$ & V. anguillarum & Gadus morhua (Denmark) & ATCC \\
\hline ATCC 33125 (biotype I) & $V$. splendidus & Marine fish (United States) & ATCC \\
\hline $95-3-51$ & VAR & Oncorhynchus mykiss (Denmark) & J. L. Larsen \\
\hline $95-3-52$ & VAR & Oncorhynchus mykiss (Denmark) & J. L. Larsen \\
\hline $95-3-101$ & VAR & Oncorhynchus mykiss (Denmark) & J. L. Larsen \\
\hline NF25.1 & VAR & Salmo salar (Spain) & F. Pazos \\
\hline $\mathrm{SE} 2.1$ & VAR & Oncorhynchus kisutch (Spain) & F. Pazos \\
\hline SE8.1 & VAR & Oncorhynchus kisutch (Spain) & F. Pazos \\
\hline RPM232.1 & VAR & Scophthalmus maximus (Spain) & F. Pazos \\
\hline RA 60.2 & VAR & Scophthalmus maximus (Spain) & F. Pazos \\
\hline RI4 1 & VAR & Scophthalmus maximus (Spain) & F. Pazos \\
\hline $\mathrm{RC} 25.1$ & VAR & Scophthalmus maximus (Spain) & F. Pazos \\
\hline RPM167.2 & VAR & Scophthalmus maximus (Spain) & F. Pazos \\
\hline $\mathrm{AZ} 1.1$ & VAR & Scophthalmus maximus (Spain) & F. Pazos \\
\hline PC23.1 & VAR & Scophthalmus maximus (Spain) & F. Pazos \\
\hline RQ1.2 & VAR & Scophthalmus maximus (Spain) & F. Pazos \\
\hline RM51 & VAR & Scophthalmus maximus (Spain) & F. Pazos \\
\hline RM36.1 & VAR & Scophthalmus maximus (Spain) & F. Pazos \\
\hline RPM 30.2 & VAR & Scophthalmus maximus (Spain) & F. Pazos \\
\hline RPM36.1 & VAR & Scophthalmus maximus (Spain) & F. Pazos \\
\hline RPM 40.1 & VAR & Scophthalmus maximus (Spain) & F. Pazos \\
\hline RPM41.1 & VAR & Scophthalmus maximus (Spain) & F. Pazos \\
\hline $95-3-71$ & VAR & Gadus morhua (Denmark) & J. L. Larsen \\
\hline $95-3-72$ & VAR & Gadus morhua (Denmark) & J. L. Larsen \\
\hline $95-3-74$ & VAR & Gadus morhua (Denmark) & J. L. Larsen \\
\hline $95-3-88$ & VAR & Gadus morhua (Denmark) & J. L. Larsen \\
\hline $95-3-89$ & VAR & Gadus morhua (Denmark) & J. L. Larsen \\
\hline $95-3-90$ & VAR & Gadus morhua (Denmark) & J. L. Larsen \\
\hline $95-3-91$ & VAR & Gadus morhua (Denmark) & J. L. Larsen \\
\hline $95-3-92$ & VAR & Gadus morhua (Denmark) & J. L. Larsen \\
\hline $95-3-93$ & VAR & Gadus morhua (Denmark) & J. L. Larsen \\
\hline $95-3-94$ & VAR & Gadus morhua (Denmark) & J. L. Larsen \\
\hline $95-3-95$ & VAR & Gadus morhua (Denmark) & J. L. Larsen \\
\hline $\mathrm{SB}$ & VAR & Morone saxatilis (United States) & A. Baya \\
\hline $88589-1$ & VAR & Tropical fish (United States) & A. Baya \\
\hline $88589-2$ & VAR & Tropical fish (United States) & A. Baya \\
\hline OG & VAR & Argopecten purpuratus (Chile) & C. Riquelme \\
\hline LL & VAR & Concholepas concholepas (Chile) & C. Riquelme \\
\hline LV29 & VAR & Seawater tank (Norway) & A. E. Toranzo \\
\hline TKI & VAR & Seawater tank (Chile) & C. Riquelme \\
\hline $95-3-33$ & VAR & Seawater (Denmark) & J. L. Larsen \\
\hline $95-3-35$ & VAR & Seawater (Denmark) & J. L. Larsen \\
\hline $95-3-41$ & VAR & Seawater (Denmark) & J. L. Larsen \\
\hline $95-3-46$ & VAR & Seawater (Denmark) & J. L. Larsen \\
\hline $95-3-48$ & VAR & Seawater (Denmark) & J. L. Larsen \\
\hline $95-3-36$ & VAR & Sediment (Denmark) & J. L. Larsen \\
\hline $95-3-47$ & VAR & Sediment (Denmark) & J. L. Larsen \\
\hline
\end{tabular}


Table 2. Phenotypic characteristics of the phena of the Vibrio strains used in this study. n: Number of strains in phenon. TCBS: thiosulfate citrate bile sucrose

\begin{tabular}{|c|c|c|c|c|}
\hline \multirow[t]{2}{*}{ Test } & \multicolumn{4}{|c|}{$\%$ of strains positive in phenon: } \\
\hline & $I(n=14)$ & II $(\mathrm{n}=23)$ & III $(n=8)$ & IV $(n=11)$ \\
\hline Motility & 100 & 100 & 100 & 100 \\
\hline Gram-negative stain & 100 & 100 & 100 & 100 \\
\hline Oxidase & 100 & 100 & 100 & 100 \\
\hline Catalase & 100 & 100 & 100 & 100 \\
\hline$\beta$-Galactosidase & 100 & 100 & 62.5 & 0 \\
\hline Arginine dihydrolase & 100 & 100 & 100 & 45.4 \\
\hline Lysine decarboxylase & 0 & 0 & 0 & 0 \\
\hline Ornithine decarboxylase & 0 & 0 & 0 & 0 \\
\hline Yellow colonies on TCBS & 100 & 100 & 0 & 100 \\
\hline Citrate utilization & 85.7 & 91.3 & 75 & 63.6 \\
\hline Urease & 0 & 0 & 0 & 0 \\
\hline Indole & 100 & 100 & 25 & 0 \\
\hline Nitrate reduction & 100 & 100 & 100 & 100 \\
\hline Gas from glucose & 0 & 0 & 0 & 0 \\
\hline Voges-Proskauer & 100 & 78.2 & 25 & 0 \\
\hline \multicolumn{5}{|l|}{ Salt tolerance $(\% \mathrm{NaCl})$} \\
\hline 0 & 0 & 0 & 0 & 0 \\
\hline 3 & 100 & 100 & 100 & 100 \\
\hline 5 & 100 & 82.6 & 100 & 100 \\
\hline 8 & 0 & 13 & 0 & 0 \\
\hline 10 & 0 & 0 & 0 & 0 \\
\hline \multicolumn{5}{|l|}{ Growth at: } \\
\hline 15 & 100 & 100 & 100 & 100 \\
\hline 25 & 100 & 100 & 100 & 100 \\
\hline 37 & 100 & 82.6 & 50 & 18.2 \\
\hline 44 & 0 & 0 & 0 & 0 \\
\hline \multicolumn{5}{|l|}{ Acid from: } \\
\hline Glucose & 100 & 100 & 100 & 100 \\
\hline Mannitol & 92.8 & 95.6 & 37.5 & 27.3 \\
\hline Inositol & 0 & 0 & 0 & 0 \\
\hline Sorbitol & 92.8 & 34.8 & 0 & 0 \\
\hline Rhamnose & 0 & 0 & 0 & 0 \\
\hline Sucrose & 100 & 100 & 100 & 91 \\
\hline Melibiose & 0 & 0 & 0 & 0 \\
\hline Amygdalin & 71.4 & 60.9 & 1.2 .5 & 18.2 \\
\hline Arabinose & 100 & 8.7 & 0 & 9 \\
\hline \multicolumn{5}{|l|}{ Hemolysis of erythrocytes: } \\
\hline Sheep & 57.1 & 34.8 & 50 & 0 \\
\hline Turbot & 92.8 & 100 & 100 & 0 \\
\hline \multicolumn{5}{|l|}{ Production of: } \\
\hline Amilase & 85.7 & 65.2 & 100 & 9 \\
\hline Gelatinase & 100 & 95.6 & 100 & 9 \\
\hline Caseinase & 100 & 87 & 100 & 18.2 \\
\hline Elastase & 71.4 & 13 & 0 & 0 \\
\hline Lipase & 71.4 & 87 & 50 & 0 \\
\hline Lecithinase & 57.1 & 100 & 87.5 & 0 \\
\hline \multicolumn{5}{|l|}{ Sensitivity to: } \\
\hline Vibriostatic agent $(O / 129)$ & 100 & 100 & 100 & 100 \\
\hline Chloramphenicol & 100 & 100 & 87.5 & 100 \\
\hline Ampicillin & 0 & 21.7 & 12.5 & 0 \\
\hline Oxytetracycline & 100 & 100 & 75 & 100 \\
\hline Tetracycline & 92.8 & 100 & 87.5 & 91 \\
\hline Oxolinic acid & 100 & 91.3 & 50 & 100 \\
\hline Streptomycin & 7 & 4.3 & 0 & 0 \\
\hline Trimethoprimsulphamethoxazole & 71.4 & 87 & 50 & 72.7 \\
\hline
\end{tabular}




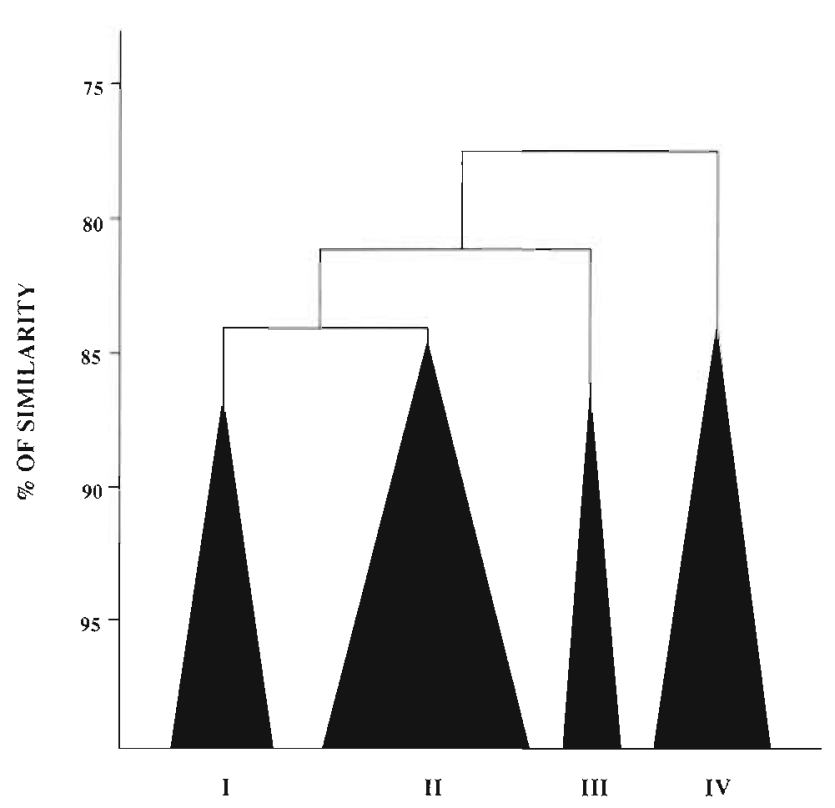

Fig. 1. Simplified dendrogram showing relationships among Vibrio stains determined by simple matching coefficients and the unweighted pair group method with arithmetic averages

Phenon IV included 11 isolates which lacked lecithinase, lipase, elastase, and hemolytic activities.

\section{Serological testing}

The slide agglutination test demonstrated that 22 of 45 VAR strains tested ( $49 \%$ ) were typeable, being distributed into 7 serogroups $(A, B, C, D, E, F, G)$ (Table 3 ). There were no cross reactions between groups. The majority of the typeable VAR strains were isolated from cod Gadus morhua (11 isolates) and turbot Scophthalmus maximus (9 isolates). While strains from cod exclusively belonged to serogroups $F$ (10 of 11 strains) and $G$ ( 1 of 11 strains), more heterogeneity was observed among turbot isolates (Table 3). Among strains isolated from the environment (seawater and sediment), no type predominated. None of the VAR strains agglutinated with the Vibrio anguillarum (serotypes $\mathrm{O} 1$ to $\mathrm{O} 10$ ) or $V$. splendidus (biotype I) antisera.

The quantitative agglutination assays confirmed the existence of 7 serogroups and indicated the existence of 2 serological subgroups within serogroup $F$ (Table 3).

Phenon I grouped the majority of the reference strains of Vibrio anguillarum (serotypes $\mathrm{O} 1, \mathrm{O} 2, \mathrm{O} 3$, O4, O6, O7, and O10), 3 strains isolated from cod and belonging to serogroup $F, 2$ strains of serogroup $G$ (isolated from cod and rainbow trout), and 2 non-typeable strains (RPM 232.1 and LV 29). Phenon II included the $V$. anguillarum strains of serotypes 05,08 , and 09 , the remaining strains of serogroup $F$ isolated from cod, 1 strain isolated from seawater and belonging to serogroup $E$, and 12 non-typeable strains from different sources. Only 3 of the strains included in Phenon III were typeable, displaying a positive reaction with the antisera against the strain of $V$ splendidus ATCC 33125 (only the homologous strain) and against strain RC25.1 (2 isolates, serogroup B). Phenon IV included the strains isolated from turbot belonging to serogroups $A, C$, and D, as well as 4 non-typeable strains.

\section{DISCUSSION}

Vibriosis due to Vibrio anguillarum is one of the most important bacterial diseases of fish throughout the world. Recently, other Vibrio species taxonomically related to $V$. anguillarum, and commonly considered environmental strains without pathogenic importance, have been associated with the disease in marine fish and shellfish. Identification of Vibrio species that possess similar morphological, physiological and biochemical characteristics is not easy because of the large number of tests that are involved and the existence of variable reactions within each species (Bryant et al. 1986a, b, Fouz et al. 1990, Pazos et al. 1993). Alternatively, serological methods are a fast and reliable way of identifying of Vibrio species as well as for use in epidemiological and ecological studies (Sørensen \& Larsen 1986, Fouz et al. 1990, Chen et al. 1992, Pazos et al. 1993, Santos et al. 1995). At present, few studies (Fouz et al. 1990) on the serological relationships among VAR strains have been conducted. This paper reports the phenotypic and serological characterization of VAR organisms isolated from diseased fish and shellfish and from the environment.

The results of the biochemical studies showed heterogeneity within Vibrio anguillarum and VAR organisms. Examination of numerical taxonomy showed that Vibrio strains were distributed in 4 phena with values of internal similarity ranging from 84.1 to $86.8 \%$. Moreover, Phena II to IV, which are composed of related vibrios, differed from $V$. anguillarum in the Indol and Voges-Proskauer reaction, the hydrolisis of elastin, fermentation of arabinose and mannitol. These findings are similar to those obtained by Bryant et al. (1986a), Fouz et al. (1990) and Romalde et al. (1990). Therefore, these phena can be considered to consist of the same species of vibrios described by these authors ( $V$. pelagius, $V$. splendidus, and Vibrio spp.). In keeping with results previously reported by other authors (Fouz et al. 1990, Myhr et al. 1991), no taxonomical differences were observed between Vibrio strains iso- 
Table 3. Slide agglutination test and quantitative agglutination assay with O-antigen from 45 VAR strains and rabbit whole-cell antisera against 7 VAR strains. VAR organisms were not typeable with the sera raised against Vibrio anguillarum of serotypes O1 to $O 10$ or with serum against $V$. splendidus (biotype I). Sero.: serogroup. Values in parentheses indicate titers obtained on quantitative agglutination test. Titers lower than 20 were scored as negative

\begin{tabular}{|c|c|c|c|c|c|c|c|c|}
\hline \multirow{2}{*}{$\begin{array}{l}\text { Bacterial } \\
\text { strain }\end{array}$} & \multirow[t]{2}{*}{ Phenon } & \multicolumn{7}{|c|}{ Antisera against VAR strain: } \\
\hline & & $\begin{array}{c}\text { RM51 } \\
\text { (Sero. A) }\end{array}$ & $\begin{array}{c}\text { RC25.1 } \\
\text { (Sero. B) }\end{array}$ & $\begin{array}{l}\text { RPM30.2 } \\
\text { (Sero. C) }\end{array}$ & $\begin{array}{l}\text { RM36.1 } \\
\text { (Sero. D) }\end{array}$ & $\begin{array}{c}95-3-35 \\
\text { (Sero. E) }\end{array}$ & $\begin{array}{l}95-3-72 \\
\text { (Sero. F) }\end{array}$ & $\begin{array}{r}95-3-88 \\
\text { (Sero. G }\end{array}$ \\
\hline \multicolumn{9}{|l|}{ Rainbow trout } \\
\hline $95-3-51$ & IV & - & - & - & - & - & - & - \\
\hline $95-3-101$ & II & - & - & - & - & - & - & - \\
\hline $95-3-52$ & I & - & - & - & - & - & - & $+(640)$ \\
\hline \multicolumn{9}{|l|}{ Atlantic salmon } \\
\hline NF25.1 & II & - & - & - & - & - & - & - \\
\hline \multicolumn{9}{|l|}{ Pacific salmon } \\
\hline SE2.1 & III & - & - & - & - & - & - & - \\
\hline SE8.1 & IV & - & - & - & - & - & - & - \\
\hline \multicolumn{9}{|l|}{ Turbot } \\
\hline RPM232.1 & I & - & - & - & - & - & - & - \\
\hline RA 60.2 & III & - & - & - & - & - & - & - \\
\hline RI41 & III & - & - & - & - & - & - & - \\
\hline AZ1.1 & IV & - & - & - & - & - & - & - \\
\hline PC23.1 & IV & - & - & - & - & - & - & - \\
\hline RC25.1 & III & - & $+(320)$ & - & - & - & - & - \\
\hline RPM167.2 & III & - & $+(320)$ & - & - & - & - & - \\
\hline RM51 & IV & $+(320)$ & - & - & - & - & - & - \\
\hline RQ1.2 & IV & $+(320)$ & - & - & - & - & - & - \\
\hline RM36. 1 & IV & - & - & - & $+(320)$ & - & - & - \\
\hline RPM30.2 & IV & - & - & $+(2560)$ & - & - & - & - \\
\hline RPM36.1 & IV & - & - & $+(1280)$ & - & - & - & - \\
\hline RPM40.1 & IV & - & - & $+(2560)$ & - & - & - & - \\
\hline RPM41.1 & IV & - & - & $+(2560)$ & - & - & - & - \\
\hline \multicolumn{9}{|l|}{ Cod } \\
\hline $95-3-71$ & II & - & - & - & - & - & $+(640)$ & - \\
\hline $95-3-72$ & II & - & - & - & - & - & $+(1280)$ & - \\
\hline $95-3-74$ & II & - & - & - & - & - & $+(1280)$ & - \\
\hline $95-3-89$ & II & - & - & - & - & - & $+(80)$ & - \\
\hline $95-3-90$ & II & - & - & - & - & - & $+(40)$ & - \\
\hline $95-3-91$ & I & - & - & - & - & - & $+(640)$ & - \\
\hline $95-3-92$ & II & - & - & - & - & - & $+(40)$ & - \\
\hline $95-3-93$ & II & - & - & - & - & - & $+(40)$ & - \\
\hline $95-3-94$ & I & - & - & - & - & - & $+(1280)$ & - \\
\hline $95-3-95$ & I & - & - & - & - & - & $+(1280)$ & - \\
\hline $95-3-88$ & I & - & - & - & - & - & - & $+(1280)$ \\
\hline \multicolumn{9}{|l|}{ Striped bass } \\
\hline SB & II & - & - & - & - & - & - & - \\
\hline \multicolumn{9}{|l|}{ Tropical fish } \\
\hline 88589-1 & III & - & - & - & - & - & - & - \\
\hline $88589-2$ & III & - & - & - & - & - & - & - \\
\hline \multicolumn{9}{|l|}{ Scallop } \\
\hline$O G$ & II & - & - & - & - & - & - & - \\
\hline \multicolumn{9}{|l|}{ 'Loco' } \\
\hline LL & II & - & - & - & - & - & - & - \\
\hline \multicolumn{9}{|l|}{ Seawater } \\
\hline $95-3-35$ & II & - & - & - & - & $+(1280)$ & - & - \\
\hline $95-3-33$ & II & - & - & - & - & - & - & - \\
\hline $95-3-41$ & II & - & - & - & - & - & - & - \\
\hline $95-3-46$ & II & - & - & - & - & - & - & - \\
\hline $95-3-48$ & II & - & - & - & - & - & - & - \\
\hline TKI & II & - & - & - & - & - & - & - \\
\hline LV 29 & I & - & - & - & - & - & - & - \\
\hline \multicolumn{9}{|l|}{ Sediment } \\
\hline $95-3-36$ & II & - & - & - & - & - & - & - \\
\hline $95-3-47$ & II & - & - & - & - & - & - & - \\
\hline
\end{tabular}


lated from diseased fish and from the environment on the basis of classical biochemical tests used in this study.

The serological analysis showed the existence of serological heterogeneity among VAR strains, with 7 serogroups (A, B, C, D, E, F, G) (Table 3) being established. Six of these serogroups ( $A, B, C, D, F$, and $G$ ) were recognized among 21 VAR strains isolated from diseased fish. Serotypes $C$ and $F$ were found to be the predominant types among strains isolated from diseased turbot and cod, respectively. Only $11 \%$ of strains isolated from the environment were typeable and none belonged to the serogroups detected among strains isolated from diseased fish. This raises a question about the possible source of pathogenic serogroups. Further studies, including a higher number of environmental strains and their respective antisera, are needed in order to clarify the origin of the pathogenic strains.

On the other hand, it was found that VAR strains of serogroups A, B, C, D, E, and G constitute homogeneous groups, while serogroup $F$ constitutes a heterogeneous group with regard to phenotypic and serological characteristics. The existence of variability with respect to biochemical and serological characteristics has also been reported for strains belonging to serotypes $\mathrm{O} 2$ and $\mathrm{O} 3$ of Vibrio anguillarum (Toranzo et al. 1987, Larsen et al. 1994, Santos et al. 1995).

In conclusion, we have found that VAR strains can be typed on the basis of the serologically distinct heatstable O-antigen. Attempts are currently being made to expand the serotyping system to enable it to characterize a higher proportion of VAR strains. In addition, the present results suggest that the formulation of present vibriosis vaccines may be improved if VAR strains representative of the antigenic groups which predominate in a particular area are tested in trial vaccines.

Acknowledgements. This investigation was supported by Grant Nos. AGF 94-1360-C03-01 from the Comisión Interministerial de Ciencia y Tecnología (CICYT) of Spain and XUGA. 200049A94 from the Xunta de Galicia (Spain). The authors are indebted to the donors for the kind supply of the strains used in this study. We also acknowledge Dr J. L. Larsen for providing the antisera against Vibrio anguillarum (serotypes O1 to O10). F.P. thanks the Xunta de Galicia for the research fellowship.

\section{LITERATURE CITED}

Bryant TN, Lee JV, West PA, Colwell RR (1986a) Numerical classification of species of Vibrio and related genera. J Appl Bacteriol 61:437-467

Bryant TN, Lee JV, West PA, Colwell RR (1986b) A probability matrix for the identification of species of Vibrio and related genera. J Appl Bacteriol 61:469-480

Castro D, Martínez-Manzanares E, Luque A, Fouz B, Morinigo MA, Borrego JJ, Toranzo AE (1992) Characteri- zation of strains related to brown ring disease outbreaks in southwestern Spain. Dis Aquat Org 14:229-236

Chen D, Hanna PJ, Altmann K, Smith A, Moon P, Hammond LS (1992) Development of monoclonal antibodies that identify Vibrio species commonly isolated from infections of humans, fish, and shellfish. Appl Environ Microbiol 58: $3694-3700$

Fouz B, Conchas RD, Bolinches J, Romalde JL, Barja JL, Toranzo AE (1990) Relationship among pathogenic Vibrio anguillarum and Vibrio tubiashii with environmental vibrios. In: Perkins FO, Chen TC (eds) Pathology in marine science. Academic Press, New York, p 7-89

Larsen JL, Pedersen K, Dalsgaard I (1994) Vibrio anguillarum serovars associated with vibriosis in fish. J Fish Dis 17: $259-267$

Lavilla-Pitogo CR, Baticados MCL, Cruz-Lacierda ER, de la Peña LD (1990) Occurrence of luminous bacterial diseases of Penaeus monodon larvae in the Philippines. Aquaculture 65:15-29

Masumura K, Yasunobu H, Okada N, Muroga K (1989) Isolation of a Vibriosp. the causative bacterium of intestinal necrosis of Japanese flounder larvae. Fish Pathol 24:135-141

Myhr E, Larsen JL, Lillehaug A, Gudding $R$, Heum $M$, Håstein $T$ (1991) Characterization of Vibrio anguillarum and closely related species isolated from farmed fish in Norway. Appl Environ Microbiol 57:2750-2757

Paillard C, Maes P (1990) Etiologie de la maladie de l'anneau brun chez Tapes philippinarum: pathogénicité d'un Vibrio sp. CR Acad Sci 310:15-20

Pazos F, Santos Y, Magariños B, Bandín I, Núñez S, Toranzo AE (1993) Phenotypic characteristics and virulence of Vibrio anguillarum-related organisms Appl Environ Microbiol 59:2969-2976

Riquelme C, Hayashida G, Toranzo AE, Vilches J, Chavez P (1995) Pathogenicity studies on a Vibrio anguillarumrelated (VAR) strain causing an epizootic in Argopecten purpuratus larvae cultured in Chile. Dis Aquat Org 22: 135-141

Romalde JL, Barja JL, Toranzo AE (1990) Vibrios associated with red tides caused by Mesodinium rubrum. Appl Environ Microbiol 56:3615-3619

Santos Y, Bandín I, Nunez S, Gravningen $K$, Toranzo AE (1991) Protection of turbot Scophthalmus maximus (L.) and rainbow trout, Oncorhynchus mykiss (Richardson), against vibriosis using two different vaccines. J Fish Dis 14:407-411

Santos Y, Pazos F, Bandín I, Toranzo AE (1995) Analysis of antigens present in the extracellular products and cell surface of Vibrio anguillarum serotypes O1, O2, and O3. Appl Environ Microbiol 61:2493-2498

Sneath PHA (1972) Computer taxonomy. In: Norris JR, Ribbons DW (eds) Methods in microbiology, Vol $7 \mathrm{~A}$. Academic Press, London, p 29-98

Sørensen UBS, Larsen JL (1986) Serotyping of Vibrio anguilIarum. Appl Environ Microbiol 51:593-597

Toranzo AE, Barja JL (1990) A review of the taxonomy and seroepizootiology of Vibrio anguillarum, with special reference to aquaculture in the northwest of Spain. Dis Aquat Org 9:73-82

Toranzo AE, Santos Y, Bandín I, Romalde JL, Ledo A, Fouz B, Barja JL (1990) A five years survey of bacterial fish infections in continental and marine aquaculture in northwest of Spain. World Aquacult 21:91-93

Toranzo AE, Santos Y, Lemos ML, Ledo A, Bolinches J (1987) Homology of Vibrio anguillarum strains causing epizootics in turbot, salmon and trout reared on the Atlantic coast of Spain. Aquaculture 67:41-52 